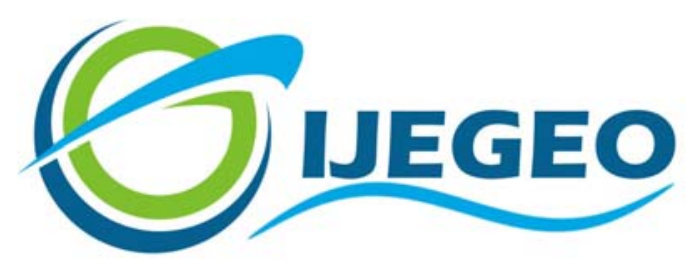

International Journal of Environment and Geoinformatics (IJEGEO) is an international, multidisciplinary, peer reviewed, open access journal.

\title{
Preparation of Silica based C8 Packing Material from Non-Toxic Water Glass
}

\author{
Abdullah AKSU., Omer S. TASKIN., Mehmet E. CETINTASOGLU., \\ Nagihan E. KORKMAZ., Cihan TORLAK., Nuray CAGLAR (BALKIS)
}

\author{
Chief in Editor
}

Prof. Dr. Cem Gazioğlu

Co-Editors

Prof. Dr. Dursun Zafer Şeker, Prof. Dr. Şinasi Kaya,

Prof. Dr. Ayşegül Tanık and Assist. Prof. Dr. Volkan Demir

Editorial Committee (August 2020)

Assos. Prof. Dr. Abdullah Aksu (TR), Assit. Prof. Dr. Uğur Algancı (TR), Prof. Dr. Bedri Alpar (TR), Prof. Dr. Lale Balas (TR), Prof. Dr. Levent Bat (TR), Prof. Dr. Paul Bates (UK), İrşad Bayırhan (TR), Prof. Dr. Bülent Bayram (TR), Prof. Dr. Luis M. Botana (ES), Assos. Prof. Dr. Gürcan Büyüksalih (TR), Prof. Dr. Nuray Çă̆lar (TR), Prof. Dr. Sukanta Dash (IN), Dr. Soofia T. Elias (UK), Prof. Dr. A. Evren Erginal (TR), Assoc. Prof. Dr. Cüneyt Erenoğlu (TR), Dr. Dieter Fritsch (DE), Prof. Dr. Çiğdem Göksel (TR), Prof. Dr. Lena Halounova (CZ), Prof. Dr. Manik Kalubarme (IN), Dr. Hakan Kaya (TR), Assist. Prof. Dr. Serkan Kükrer (TR), Assoc. Prof. Dr. Maged Marghany (MY), Prof. Dr. Michael Meadows (ZA), Prof. Dr. Nebiye Musaoğlu (TR), Prof. Dr. Masafumi Nakagawa (JP), Prof. Dr. Hasan Özdemir (TR), Prof. Dr. Chryssy Potsiou (GR), Prof. Dr. Erol Sarı (TR), Prof. Dr. Maria Paradiso (IT), Prof. Dr. Petros Patias (GR), Prof. Dr. Elif Sertel (TR), Prof. Dr. Nüket Sivri (TR), Prof. Dr. Füsun Balık Şanlı (TR), Prof. Dr. Uğur Şanlı (TR), Duygu Ülker (TR), Prof. Dr. Seyfettin Taş (TR), Assoc. Prof. Dr. Ömer Suat Taşkın (US), Dr. İnese Varna (LV), Dr. Petra Visser (NL), Prof. Dr. Selma Ünlü (TR), Assoc. Prof. Dr. İ. Noyan Yılmaz (AU), Prof. Dr. Murat Yakar (TR), Assit. Prof. Dr. Sibel Zeki (TR)

Abstracting and Indexing: TR DIZIN, DOAJ, Index Copernicus, OAJI, Scientific Indexing Services, International Scientific Indexing, Journal Factor, Google Scholar, Ulrich's Periodicals Directory, WorldCat, DRJI, ResearchBib, SOBIAD 


\title{
Preparation of Silica based $\mathrm{C}_{8}$ Packing Material from Non-Toxic Water Glass
}

\author{
Abdullah Aksu', (iD) Omer S. Taskin ${ }^{1, *}$, (iD) Mehmet E. Cetintasoglu' ${ }^{1}$, (D) Nagihan E. Korkmaz ${ }^{1}$, \\ Cihan Torlak ${ }^{2}$, iD Nuray Caglar (Balkis) ${ }^{1}$ (iD \\ ${ }^{1}$ Istanbul University, Institute of Marine Science and Management, Department of Chemical Oceanography, Vefa, 34134, Istanbul, TR \\ ${ }^{2}$ Kirklareli University, Department of Chemistry, Kayali 39060, Kirklareli, TR.

How to cite: Aksu et al, (2020). Preparation of Silica based $\mathrm{C}_{8}$ Packing Material from Non-Toxic Water Glass. Journal of Environment and Geoinformatics (IJEGEO), 7(2): 127-131. DOI: 10.30897/ijegeo.700599

\begin{abstract}
Synthesize of low price stationary phases with permanent groups for reversed-phase liquid chromatography (RP-HPLC) has gained great importance in the past several years. In chromatographic analyses, silica gels are commonly used as a supporting material as they give high mechanical strength and swelling resistance. Additionally, different particle and pore size availability and low cost makes these materials one of the most suitable stationary phase. In this work, chemically bonded $\mathrm{C}_{8}$ phase was synthesized by sol-gel route and instead of toxic silicone alkoxides, non-toxic water glass was chosen as a precursor. Linking process of $\mathrm{C}_{8}$ groups to silica gel was carried out by trimethoxy(octyl)silane. The end-capping and $\mathrm{C}_{8}$ binding procedure was analyzed by Fourier transform infrared (FTIR) spectroscopy and morphology of $\mathrm{C}_{8}$ particles were characterized by scanning electron microscope (SEM).
\end{abstract}

Keywords: Water glass, $\mathrm{C}_{8}$ packing material, HPLC.

\section{Introduction}

In today's technology, chromatographic applications need faster analyses and more efficient columns compared to past years. For instance, in pharmacokinetic researches, mixture separation needs to be rapid and in molecular biological studies in order to analyze complex mixtures, efficient columns are required. Moreover, as the concentration range of examined chemicals has extended, new columns should offer high load ability to prevent the efficiency loss if a column is overloaded (Morbidelli et al., 2006). Therefore, designing of constant filling phases for reversed-phase liquid chromatography was dominated by alkyl modified silica sorbents. These materials improve mechanical strength and allow production of different morphologies by various pore size and particle diameter that leads to get highly efficient packed columns (Brown et al., 2017; Taskin et al., 2015; Unger, 1979; Unger et al., 1976; Unger et al., 1972).

There are two different kinds of chemically bonded phases (Coating-poly layer phases and Halasz brush phases) that were utilized in recent HPLC applications (Buszewski et al., 1998). Both types of phases were successfully used in different pharmaceutical, environmental and medical and applications. Diol, $\mathrm{NH}_{2}$, $\mathrm{Ph}, \mathrm{C}_{2}, \mathrm{C}_{8}$ and $\mathrm{C}_{18}$ can be given as an example for brush stationary phases (Sykora et al., 1997; Balc1oglu et al., 2014; Aksu and Taskin, 2012). Synthesizing procedure is also as important as functional groups. There are several ways to obtain spherical morphology for silica gel. One of them is getting small droplets by spraying a colloidal silica solution before gelation was occurred. Second one is dispersion of silica sol in the form of an emulsion by using organic solvent (Unger, 1972). Another method to produce spherical particle is using non-aqueous solvents (Berek and Novak, 1990; Taskin et al., 2014; Taskin et al., 2015; Taskin et al., 2015; Ugelstad et al., 1980).

There are some problems for using abovementioned routes to obtain spherical silica particles (Cacace and Mazza, 2006; Unger, 1990; Yuca et al., 2018; Taskin et al., 2018). The most crucial one is managing microstructure and particle size of silica gel beads or granules. In this study to overcome this issue emulsion polymerization and sol gel methods were used together. Silica gel powders were synthesized via emulsion polymerization, where the droplets of monomers (silicic acid) were emulsified with surfactants in a continuous phase of hexane. After the gelation of the silicic acid droplets, surface of the attained silica gel powders were modified with hexamethyldisilazane. In order to reduce the production cost glass water was chosen as a silica resource instead of commercial TEOS and ambient pressure drying was applied instead of supercritical drying. Some physical properties and the microstructure of the silica gel powders were examined.

\section{Materials and Methods}

Water glass (sodium silicate solution) was used as a precursor to attain silicic acid. Firstly, water glass (Koruma Chemistry Cor., Turkey) - water mixture was prepared where water glass has $9 \mathrm{wt} \%$ ratio to water. 
After dilution process, prepared solution poured into an ion exchange resin (acidic resin) containing column (Purolite C104Plus) to obtain silicic acid droplets. In order to get microsphere morphology, $4 \mathrm{ml}$ of surfactant (Span ${ }^{\circledR} 80$ nonionic surfactant) and silicic acid solution from previous treatment was mixed with n-hexane.

Stirring process of silicic acid solution was performed in an n-hexane media at $2800 \mathrm{rpm}$ for 7 minutes by using a homogenizer (IKA, T25 D, Germany). Ammonium hydroxide was used to reduce the $\mathrm{pH}$ value of the silicic acid to 5.0 and after that, silica droplets were started to gelate at room temperature for 11 hours and continued with drying process for 6 hours at $135^{\circ} \mathrm{C}$.

Reflux system was prepared for $\mathrm{C}_{8}$ bonding process and Tricholoro(octasilane) was used as a source for functional group. For reflux system toluene, pyridine, silica gel and Tricholoro(octasilane) were mixed with 10:0.5:1:2 gravimetric ratio, respectively at $260{ }^{\circ} \mathrm{C}$ for 3 hours. By adding pyridine, chloride ions that come from Trichloro(octasilane) reaction were hold and removed from system. Reflux process was advanced for 6 hours and followed by a filtration. The powders were washed with toluene, tetrahydrofuran, methanol, methanol-water solution with 1:1 volumetric ratio, respectively. Then the residual silanol groups that did not participate in the reaction was treated by silanizing agent (Hexamethyldisilazane) to react with unreacted hydroxyl groups and give hydrophobicity. Finally, $\mathrm{C}_{8}$ functional silica powders surface was modified with toluene and hexamethyldisilazane $(1: 1 \mathrm{v} / \mathrm{v})$ mixture in order to give hydrophobicity then washed with toluene, tetrahydrofuran, methanol, methanol water $(1: 1 \mathrm{v} / \mathrm{v})$ and filtered and dried under vacuum.

Making a high dense packing is the key to get clear peaks in chromatogram. Therefore, shrinkage/swelling process was applied by using solvents with different polarities in order to get high packing density. $\mathrm{C}_{8}$ functional silica powders were transferred into tetrachloroethylene - methanol $(1: 6 \mathrm{v} / \mathrm{v})$ mixture contained cup to sonicate for 8 minutes where the particles were started to shrink in the presence of a polar solvent. Afterwards attained slurry was filled into a

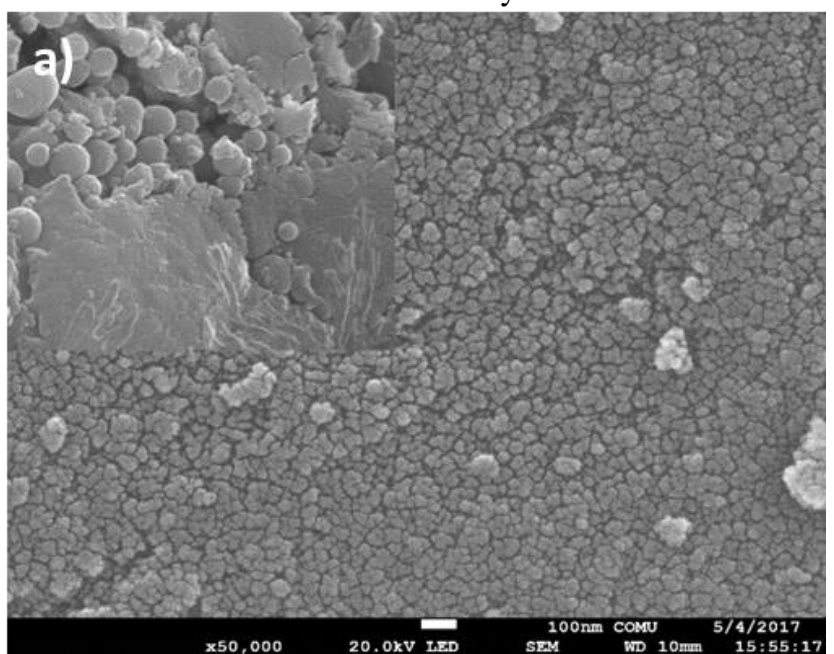

Fig. 1. SEM image of the a) silica gel b) $\mathrm{C}_{8}$ packing material. custom-made stainless steel $(904 \mathrm{~L})$ tube $(4.6 \mathrm{~mm}$ radius and $250 \mathrm{~mm}$ length) with $125 \mathrm{ml}$ methanol at $1000 \mathrm{bar}$ pressure by using a maximotor packing pump.

\section{Results}

Surface are of particles were characterized with BET analysis. The surface area of our synthesized silica gel and Sigma Aldrich's silica gel showed similar values: $602.54 \mathrm{~m}^{2} \cdot \mathrm{g}^{-1}$ and $600 \mathrm{~m}^{2} \cdot \mathrm{g}^{-1}$ respectively, even though initial precursors for commercial (Tetraethyl orthosilicate) and our silica gel (Water glass) were different.

Carbon functional $\left(\mathrm{C}_{8}\right)$ silica that was prepared by Tricholoro(octasilane) has $450.53 \mathrm{~m}^{2} \cdot \mathrm{g}^{-1}$ surface area. The reason for decrease in surface area can be explained by linking process. As $\mathrm{C}_{8}$ groups linked with silica, this process destroyed the pores inside the silica structure, which led a smaller surface area. Collapsing of pores inside the structure also observed in our two different Silica based $\mathrm{C}_{8}$ control sample (Material Harvest, Sigma Aldrich). They both showed similar results and their specific surface area were decreased to $400 \mathrm{~m}^{2} \cdot \mathrm{g}^{-1}$ from $600 \mathrm{~m}^{2} \cdot \mathrm{g}^{-1}$.

One of the most important thing is production of silica gel in spherical morphology, as it directly affects the efficiency of $\mathrm{C}_{8}$ linking to silica bone during the synthesis. This leads higher organic carbon loading than other silica gel morphologies and with higher carbon loading silica gel's polarity decreases. In order to get better results from an apolar chemical, it is important to have a high apolarity in the packing material. Therefore, spherical form of silica gel is essential for getting accurate results.

The SEM images obtained from the $\mathrm{C}_{8}$ functional silica and bare silica gel were shown in Figure 1. The Figure 1a demonstrates that there were some local agglomerations but generally, silica gel particles have spherical morphology within the range of 20 to $50 \mathrm{~nm}$. Those agglomerations can be ascribed to high heat treatment time. Similar morphological results were observed at $\mathrm{C}_{8}$ functional silica. SEM result in Figure 1.b can confirm that $\mathrm{C}_{8}$ linking process did not change the morphology and particle size.

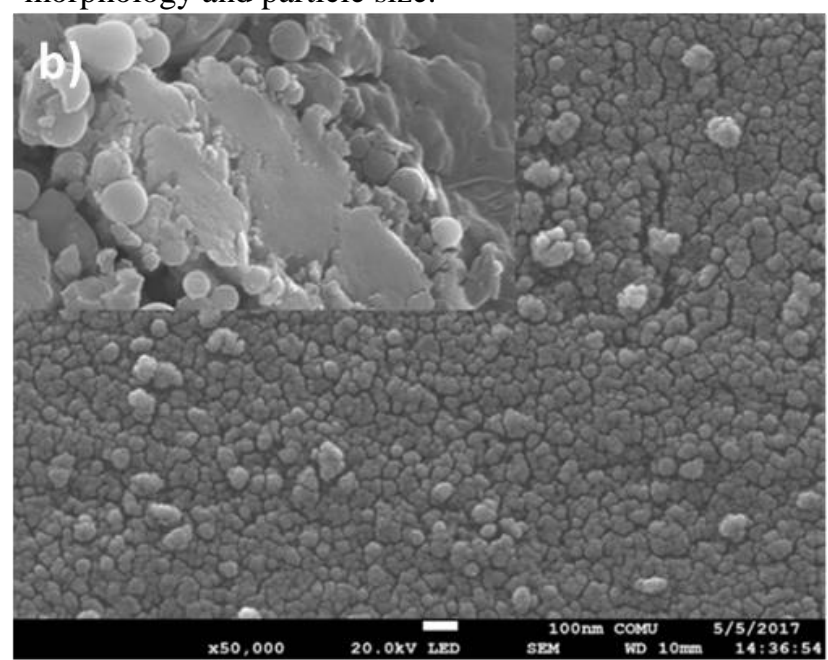



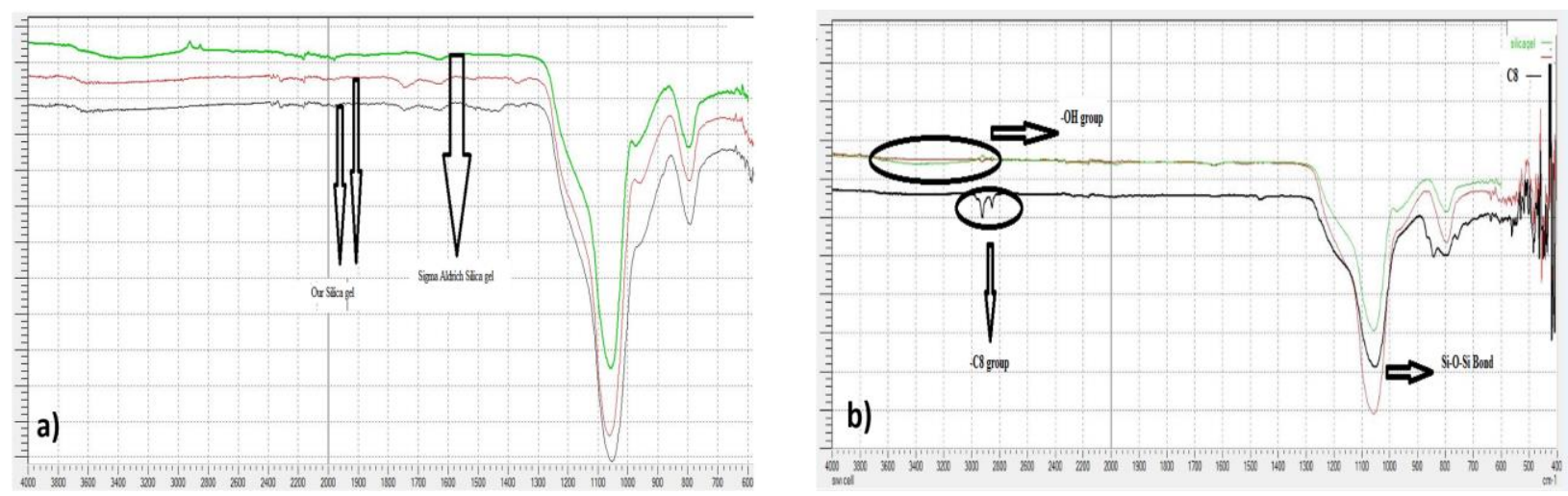

Fig. 2. FT-IR spectrum of a) silica gel b) $\mathrm{C}_{8}$ packing material.

Figure 2 shows the FT-IR spectrums of silica gel before and after linking process. Si-O-Si cross linked siloxane network structure's absorption bands can be found at $1220,1100,800$ and $460 \mathrm{~cm}^{-1}$ and Si-OH bonding can be seen between $2900-3600 \mathrm{~cm}^{-1}$ as a broad small peak.

In Figure 2b two additional peaks appeared at 2910 and $2860 \mathrm{~cm}^{-1}$ instead of $\mathrm{Si}-\mathrm{OH}$ peak that can be ascribed to $\mathrm{C}_{8}$ bonding. Those peaks occurred because of the surface modification process where the $\mathrm{Si}-\mathrm{OH}$ groups of the silica gel droplets reacted with $\mathrm{Si}-\left(\mathrm{CH}_{3}\right)_{8}$ groups of Trimethoxy(octyl)silane and $\mathrm{Si}-\left(\mathrm{CH}_{3}\right)_{6}$ groups of hexamethyldisilazane.

Elemental analyzer (Carlo Erba NC-2500) was used to determine the polarity and $\mathrm{Si}_{-} \mathrm{C}_{8}$ binding ratio for all samples. C ratio of the Sigma Aldrich silica gel, Material Harvest silica gel, trimethoxy(octyl)silane used silica gels were $9 \%, 9 \%, 10 \%$, respectively.

Chromatographic analyzes were done with liquid chromatograph system (Hewlett Packard, HP-1050). Chemstation-2 and a diode array detector was used for data acquisitions and process control. Solutes were injected by Rheodyne (Model 7125). HPLC purity water, methanol and acetonitrile were used in preparation of mobile phases with $0.5 \mathrm{~mL} / \mathrm{min}$ flow rate. In order to achieve peak separation UV detection was set to $254 \mathrm{~nm}$.

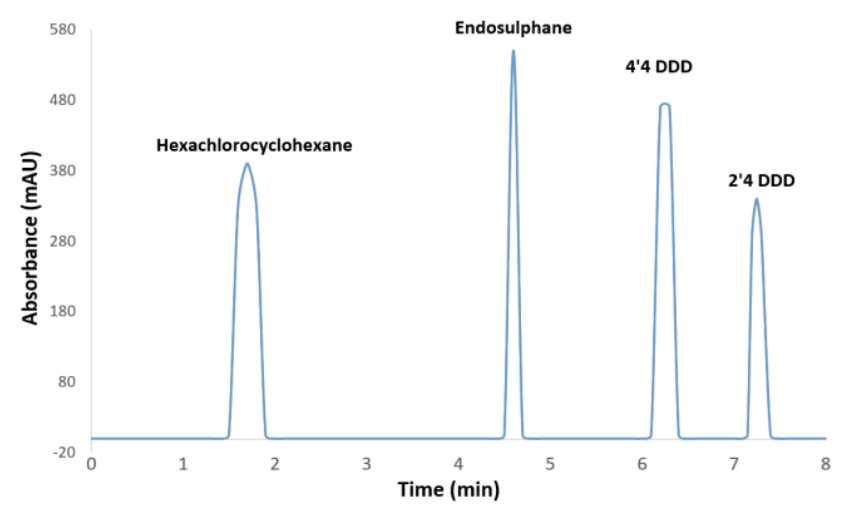

Fig. 3. Chromatogram of the prepared $C_{8}$ packed column

$\mathrm{C}_{8}$ functional silica powder's mixture chromatogram was presented in Figure 3. Difference between hexachlorocyclohexane, 4,4 dichlorodiphenyl dicholoroethane (4,4 DDD), 2,4 DDD and endosulphane indicate the chromatographic coefficients and they were showed in Table 1. To get a precise analyses retention factor ( $\mathrm{k}$ value) of materials must be between $1-10 \mathrm{~K}$ values of our sample was measured as 4.4 and that leads better peak separation in analyses.

Table 1. Column features.

\begin{tabular}{ll}
\hline Column dimension & $\mathbf{2 5 0} \mathbf{~ m m} \mathbf{4 . 6} \mathbf{m m}$ \\
\hline Particle Size & $5 \mu \mathrm{m}$ \\
Number of Tray $(\mathrm{N})$ & 18154 \\
Retention Factor $(\mathrm{k})$ & 4.4 \\
\hline
\end{tabular}

Plate height equation refers the relation between plate height and mobile phase rate. The best known is the Deemter equation, which identifies different contributions to plate height $(\mathrm{H})$. In this equation, parameters affecting the total peak width are expressed as three terms where $\mathrm{H}$ is plate height, $\mathrm{A}$ is vortex diffusion expression, $\mathrm{B}$ is longitudinal diffusion term, $\mathrm{u}$ is linear speed and $\mathrm{C}$ is resistance to mass transfer coefficient (Equation 1).

$$
\mathrm{H}=\mathrm{A}+\mathrm{B} / \mathrm{U}+\mathrm{C} \times \mathrm{u}
$$

Different column length for different plate height were analyzed and related Deemter equation that is appropriate with our results was shown in Figure 4.

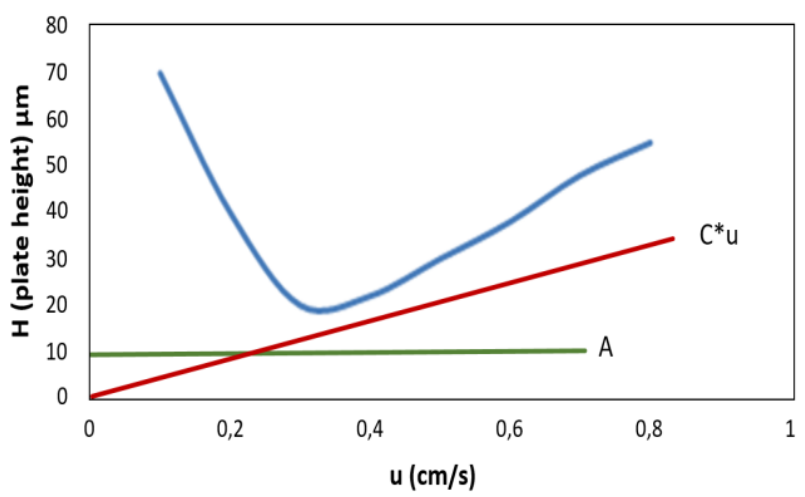

Fig. 4. Van Deemter equation of silica based $C_{8}$ packing material

Measure of peak tailing is called as asymmetry factor. It can be described as the interval from the back slope to centerline of the peak divided by the interval from the front slope to centerline of the peak. Asymmetry value of hexachlorocyclohexane for our silica based $\mathrm{C}_{8}$ 
packing material was measured as 0.98 which is between the acceptable value range $(0.9-1.2)$ (Figure 5).

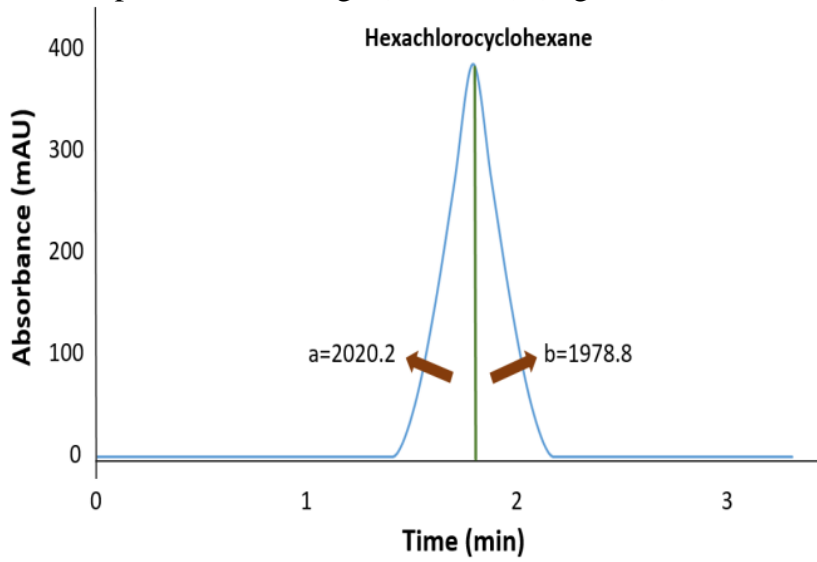

Fig. 5. Asymmetry value of hexachlorocyclohexane for silica based $\mathrm{C}_{8}$ packing material

\section{Discussion and Conclusion}

Quality of silica gel is depended on the morphology of silica particles and spherical form provided better C link to silica, which leads higher carbon loading compared to other silica gel morphologies. Therefore, spherical $\mathrm{C}_{8}$ functional silica powders for HPLC column packing materials were successfully synthesized by using emulsion polymerization and sol gel route.

Packing the HPLC column was also another crucial part. To observe the various peaks of compounds clearly and get better chromatographic coefficients, packing procedure must be done at higher pressure, therefore our $\mathrm{C}_{8}$ functional silica gel was packed at 1000 bar.

\section{Acknowledgements}

The authors thank Scientific Research Projects Unit of Istanbul University for their supports to BYP-201828592 numbered project about this study. We declare that we have no conflict of interest.

\section{References}

Aksu, A., Taskin, O.S. (2012). Organochlorine residue and toxic metal $(\mathrm{Pb}, \mathrm{Cd}$ and $\mathrm{Cr})$ levels in the surface sediments of the Marmara Sea and the coast of Istanbul, Turkey. Marine Pollution Bulletin, 64, 1060-1062.

Balcioglu, E.B., Aksu, A., Balkis, N., Ozturk, B. (2014). T-PAH contamination in Mediterranean mussels (Mytilus galloprovincialis, Lamarck, 1819) at various stations of the Turkish Straits System. Marine Pollution Bulletin, 88(1), 344-346.

Berek, D., Novák, I. (1990). Silica gel and carbon column packings for use in high-performance liquid chromatography. Chromatographia, 30(9), 582-590.

Brown, L., Earle, M.J., Gîlea, M.A., Plechkova, N.V., Seddon, K.R. (2017). Ionic liquid-liquid chromatography: a new general purpose separation methodology. Top. Curr. Chem., 375(5), 74-81.

Buszewski, B., Jezierska, M., Wełniak, M., Berek, D. (1998). Survey and trends in the preparation of chemically bonded silica phases for liquid chromatographic analysis. J. High Resolut. Chromatogr, 21(5), 267-281.

Cacace, J.E., Mazza, G. (2006). Pressurized low polarity water extraction of lignans from whole flaxseed. $J$. Food Eng., 77(4), 1087-1095.

Morbidelli, M., Guiochon, G., Felinger, A., Shirazi, D.G. (2006). Introduction to Fundamentals of Preparative and Nonlinear Chromatography, Ch. 1. Amsterdam: Elsevier.

Sýkora, D., Tesařová, E., Popl, M. (1997). Interactions of basic compounds in reversed-phase highperformance liquid chromatography influence of sorbent character, mobile phase composition, and $\mathrm{pH}$ on retention of basic compounds. J. Chromatogr. A, 758(1), 37-51.

Taskin, O.S., Aksu, A., Cetintasoglu, M.E., Korkmaz, N.E., Torlak, C., Balkis, N., (2017) Preparation of analytical columns and HPLC silica-based $\mathrm{C}_{18}$ packing material synthesis from non-toxic silica source. J. Liq. Chromatogr. Relat. Technol., 41(10), 583-587.

Taskin, O.S., Kiskan, B., Aksu, A., Balkis, N., Weber, J., Yagci, Y. (2014). Polybenzoxazine: A powerful tool for removal of mercury salts from water. Chem. Eur. J., 20(35), 10953-10958.

Taskin, O.S., Kiskan, B., Aksu, A., Balkis, N., Yagci, Y. (2015). Preparation of microporous organic polymer through Schiff base chemistry and its potential application. Des. Monomers Polym., 18(6), 567-573.

Taskin, O.S., Kiskan, B., Weber, J., Yagci, Y. (2015). One Pot, One Step strategy for the preparation of clickable melamine based microporous organic polymer network. Macromol. Mater. Eng., 300(11), 1116-1122.

Taskin, O.S., Temel, B.A., Tasdelen, M.A., Yagci, Y. (2015). Synthesis of block copolymers by selective $\mathrm{H}$-abstraction and radical coupling reactions using benzophenone/benzhydrol photoinitiating system. Eur. Polym. J., 62, 304-311.

Ugelstad, J., Mórk, P.C., Kaggerud, K.H., Ellingsen, T., Berge, A. (1980). Swelling of oligomer-polymer particles. New methods of preparation. Adv. Colloid Interface Sci., 13(1), 101-140.

Unger, K. (1972). Structure of Porous Adsorbents. Angew. Chem., 11(4), 267-278.

Unger, K. (1979). Chapter 4 Particle characteristics. In: Journal of Chromatography Library. Elsevier.

Unger, K. (1990) Packings and stationary phases in chromatographic techniques. Chromatogr. Sci. Ser., $8,47-55$.

Unger, K., (1979). Chapter 2 Pore structure of silica. In: Journal of Chromatography Library. Elsevier.

Unger, K., Scharf, B. (1976). Controlled porosity silica supports from hydrolytic polycondensation reaction of poly (ethoxysiloxane). J. Colloid Interface Sci., 55(2), 377-380.

Yuca, N., Cetintasoglu, M.E., Dogdu, M.F., Akbulut, H., Tabanli, S., Colak, U., Taskin O.S. (2018). Highly efficient poly(fluorene phenylene) copolymer as a new class of binder for high capacity silicon anode in lithium ion batteries. Int. J. Energy Res., 42(3), 11481157. 


\section{Graphical Abstract}

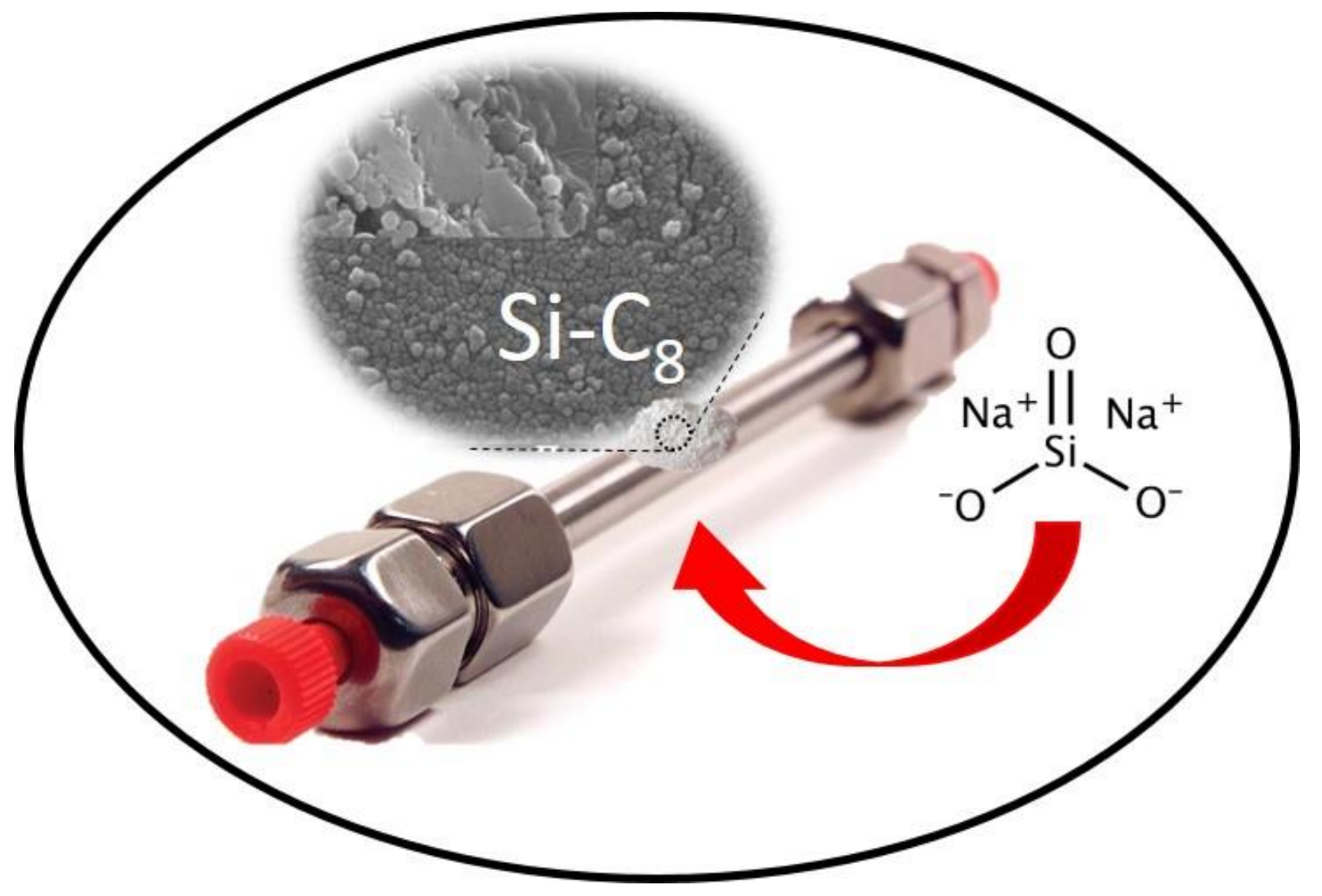

